\title{
RANCANGAN DAN PEMBUATAN ALAT SIMULASI SISTEM VENTILASI TAMBANG PADA LABORATORIUM UNTUK PEMBELAJARAN VENTILASI TAMBANG
}

\author{
Bambang Heriyadi \\ Teknik Pertambangan, Universitas Negeri Padang \\ email: bambang_heriyadi@yahoo.co.id
}

Underground mine activities is not detached by mechanical ventilation system for supplying air demand for worker's breathing, dirty air and toxic gases removing, dust reducing, and heat and humidity controlling. There for makes safer and enjoyable in working. To facility the study of mine ventilation in campus, the simulation study about mechanical underground mine ventilation system was applied. To do this research, the describtion about mechanical ventilation system of underground mine is necersary and also we need pay attention with the parameters in air qualities and quantities controlling witch are not over limit to the limit value (NAB). Describing how to control the air qualities and quantities, the writer got sample as well as PT. AICJ. PT.AICJ's ventilation system is forcing system with some parameter like air velocity, wet and dry temperature, relative humidity, tunnel dimension, and around of gases concentration in air at mine front. Gases measured to wards the concentration of $O 2$, $\mathrm{CO} 2, \mathrm{CH} 4$, and H2S. In this research, the writer designed and created a simulation of ventilation system, with autoCAD 2014 modeling advises. In the other hand the material that, used for equipment is iron plate $1 \mathrm{~mm}$ thickness. Volumetric air flow rate produced by forcing fan (18" diameter size) is $0.23 \mathrm{~m}^{3} /$ second with $26^{\circ} \mathrm{C}$ effectively temperature. Medium air flow rate is $0.24 \mathrm{~m} / \mathrm{second}$ with is $25,3^{0} \mathrm{C}$ effectively temperature. High air flow rate is $0,26 \mathrm{~m} / \mathrm{second}$ with $24,7^{\circ} \mathrm{C}$ effectively temperature, while volumetric air flow rate of forcing fan 16" diameter size is o,26 $\mathrm{m}^{3} /$ second with $24,4^{0} \mathrm{C}$ effectively temperature, for exhaust fan (4"size) produced $0,18 \mathrm{~m}^{3} / \mathrm{second}$ volumetric air flow rate with $26,5^{0} \mathrm{C}$ effectively temperature. so the simulation equipment ventilation can show measure result by quantity and quality airflow characteristic.

Keywords: Ventilation Simulation Equipment, Air Quality, Air Quantity, Ventilation Pressure

\section{PENDAHULUAN}

Sistem ventilasi pada kegiatan penambangan bawah tanah merupakan hal yang sangat penting, berbeda dengan tambang terbuka, pada tambang bawah tanah ketersediaan udara sangat terbatas. Pada tambang bawah tanah udara yang ada sangat terbatas ditambah dengan aktivitas penambangan yang menimbulkan debu sehingga keberadaan ventilasi sangat dibutuhkan dalam sistem penambangan bawah tanah.

Apabila tidak ada ventilasi dalam tambang bawah tanah akan berakibat, sulitnya para pekerja bernafas dan yang lebih buruk dapat menyebabkan kematian. Dengan adanya ventilasi yang baik pada tambang bawah tanah maka para pekerja akan merasa nyaman ketika mereka bekerja.

Pada tambang bawah tanah sistem ventilasi sangat berperan penting dalam hal pemenuhan kebutuhan udara pernafasan pekerja, membersihkan udara kotor dan gas-gas beracun, mengurangi konsentrasi debu dan juga mengatur panas dan kelembaban udara di dalam tambang sehingga tercipta kondisi kerja yang aman dan nyaman. Jika temperatur udara tidak sesuai dengan temperatur efektif yang disarankan oleh KEPMEN-555K yaitu antara $18^{\circ}-24^{\circ}$ celcius maka front kerja tersebut harus dikondisikan agar sesuai dengan persyaratan tersebut. 
Pada tambang batubara bawah tanah (underground mine), dapat diasumsikan terjadi berbagai macam sumber panas yang dapat meningkatkan suhu udara di area tambang bawah tanah. Diantaranya panas dari batuan, panas dari alat yang digunakan, dan panas dari tubuh pekerja. Ditambah dengan sistem ventilasi yang kurang baik maka peningkatan suhu di area penambangan bawah tanah tidak dapat dihindarkan.

Kemudian agar udara yang masuk ke dalam tambang bawah tanah dapat sesuai dengan kebutuhan udara yang dibutuhkan oleh para pekerja, maka diperlukan perhitungan jumlah karyawan yang bekerja di dalam tambang bawah tanah, menghitung luas penampang terowongan, menghitung kecepatan angin, jumlah angin masuk dan yang keluar dari dalam tambang bawah tanah tersebut. Untuk menciptakan kondisi kerja yang nyaman bagi pekerja, perlu dilakukan pengkajian terhadap beberapa parameter yang meliputi; jumlah dan kondisi gas, jumlah peralatan mesin yang beroperasi serta kondisi suhu dan kelembaban udara sehingga dengan dilakukan pengkajian terhadap parameter ini, dapat ditentukan kualitas dan kuantitas udara yang diperlukan untuk kelangsungan operasional yang memenuhi persyaratan kepmen 555k.

Dalam melakukan penelitian ini penulis membutuhkan gambaran tentang sistem ventilasi mekanis tambang bawah tanah serta parameter yang menjadi acuan dalam menentukan karakteristik kuantitas dan kualitas udara yang aman dalam melakukan proses penambangan dan tidak melewati nilai ambang batas (NAB). Maka PT.Allied Indo Coal Jaya Sawahlunto, menjadi acuan penulis dikarenakan melakukan penambangan batubara dengan metode tambang bawah tanah sistem room and pillar. Sistem ventilasi mekanis yang digunakan adalah sistem ventilasi hembus.

Dalam merancang suatu sistem ventilasi pada tambang bawah tanah tentu harus dipelajari aspek apa yang saja akan menjadi parameter dalam mendesain sistem ventilasi. Hal tersebut dipelajari oleh mahasiswa teknik pertambangan UNP dengan mata kuliah ventilasi tambang.

Mata kuliah ventilasi tambang dipelajari oleh mahasiswa secara teori dan praktek. Namun kenyataannya pembelajaran banyak berfokus pada teori saja, karena ketiadaan alat simulasi pembelajaran ventilasi tambang. Pratikum pada kuliah ventilasi tambang dilakukan melalui kunjungan langsung ke lapangan, pada perusahaan yang melakukan metode penambangan secara tambang bawah tanah. kegiatan dilakukan dengan intensitas yang sedikit, sehingga ilmu secara praktek mengenai ventilasi tambang dirasa kurang. Permasalhan yang diungkap pada penelitian ini adalah Apa saja parameter pengukuran yang dilakukan untuk memastikan kualitas dan kuantitas udara pada tambang bawah tanah terpenuhi sesuai aturan yang berlak, Bagaimana bentuk rancangan dan hasil pembuatan alat simulasi sistem ventilasi tambang bawah tanah yang dapat menggambarkan pemantauan kualitas dan kuantitas udara dapat dilakukan, sebagaimana pada kondisi nyata di tambang bawah tanah, Parameter apa saja yang bisa diukur dan diungkapkan dari alat simulasi sistem ventilasi tambang bawah tanah yang telah dirancang dan dibuat.

Tujuan dai penelitian ini adalah Mengungkapkan cara pengukuran kualitas dan kuantitas udara pada tambang bawah tanah PT.AICJ, Mendapatkan parameter apa saja yang diukur pada pengendalian kualitas dan kuantitas udara di PT.AICJ, sekaligus mendapatkan nilai hasil pengukuran dan membandingkannya dengan nilai standar yang ada, Menghasilkan rancangan dan sekaligus membuat alat simulasi sistem ventilasi tambang bawah tanah, untuk pembelajaran mata kuliah ventilasi tambang, serta Menguji coba alat simulasi sistem ventilasi tambang bawah tanah yang telah dirancang dan dibuat, serta mengungkapkan 
parameter apa saja yang dapat diperoleh dari alat simulasi tersebut.

\section{METODOLOGI}

Tahapan pekerjaan penelitian sebagai berikut :

1. Studi Literatur

Mempelajari teori-teori yang berhubungan dengan materi yang akan dibahas di lapangan melalui buku-buku, jurnal dan sumber lainnya.

2. Pengambilan Data

Data yang diambil berupa data primer dan data sekunder. Untuk data primer diambil langsung di pada alat simulasi yaitu : (pengukuran kecepatan udara, pengukuran dimensi saluran, , kelembaban udara, temperatur,. Sedangkan untuk data sekunder didapat dari skripsi atau laporan mahasiswa sebelumnya yaitu : (peta layout penambangan, parameter yang diambil oleh perusahaan.

3. Pengolahan Data

Analis pengolahan data bertujuan untuk :

a. Membuat rancangan dan alat simulasi sistem jaringan ventilasi

b. Perhitungan kualitas dan kuantitas udara dari hasil simulasi.

c. Menghitung efisiensi kerja dari data temperature hasil simulasi

4. Kesimpulan dan Saran

Kesimpulan diperoleh dari hasil perhitungan, dan analisis data simulasi.

Serta saran-saran agar apa yang direkomendasikan bisa dijadikan pertimbangan untuk peningkatan guna alat.

\section{HASIL DAN PEMBAHASAN}

Hasil dan pembahasan pada penilitian ini adalah mengenal evaluasi kualitas dan kuantitas udara. Alat simulasi ventilasi tambang bawah tanah sebagai pembelajaran mata kuliah ventilasi tambang jurusan teknik pertambangan UNP.

\subsection{Hasil rancangan alat simulasi ventilasi tambang bawah tanah}

Rancangan alat simulasi mengunakan software autocad 2014. Berikut gambar desain alat simulasi ventilasi tambang.

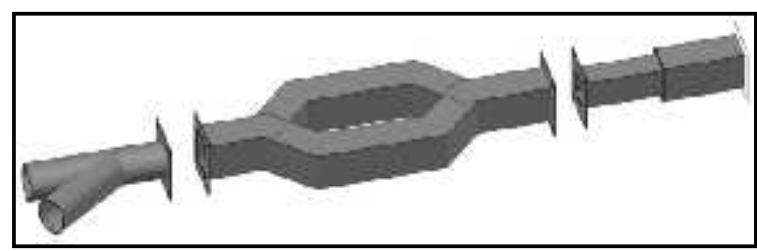

Gambar 1. Desain Realistik 3d Alat

\subsection{Hasil Analisis Udara pada Alat Simulasi}

Kuantitas udara dihitung berdasarkan hasil kali kecepatan udara dengan luas penampang yang dilawatinya dengan menggunakan rumus :

Keterangan :

$$
Q=V x A
$$

$\mathrm{Q}=$ Kuantitas udara, $\mathrm{m}^{3} /$ detik

$\mathrm{V}=$ Kecepatan aliran udara tambang, $\mathrm{m} /$ detik

$\mathrm{A}=$ Luas penampang jalan udara tambang, $\mathrm{m}^{2}$

Dari evaluasi kebutuhan udara di atas dapat diambil kesimpulan bahwa debit udara yang dapat disuplai oleh fan dapat mencapai ujung saluran dengan rata-rata untuk fan hembus ukuran 18"dan fan hisap $0.16 \mathrm{~m}^{3} /$ detik, dan fan hembus ukuran 16 " $0.53 \mathrm{~m}^{3} /$ detik.Berikut data kuantitas udara pada ujung saluran dan buangan pada masing- masing fan.

Tabel 1. Kuantitas udara pada ujung saluran dan point E masing- masing fan

\begin{tabular}{|c|c|c|c|c|}
\hline jenis fan & lokasi & $\begin{array}{c}\mathrm{V} \\
\text { (udara) } \\
(\mathrm{m} / \text { detik })\end{array}$ & $\begin{array}{c}\mathrm{A} \\
\left(\mathrm{m}^{2}\right)\end{array}$ & $\begin{array}{c}\mathrm{Q} \\
\left(\mathrm{m}^{3} / \text { detik }\right)\end{array}$ \\
\hline $\begin{array}{c}\text { hembus } \\
18 \text { " low }\end{array}$ & $\begin{array}{c}\text { ujung } \\
\text { saluran }\end{array}$ & 2,405 & 0,096 & 0,231 \\
\hline $\begin{array}{c}\text { hembus } \\
18 " \\
\text { medium }\end{array}$ & $\begin{array}{c}\text { ujung } \\
\text { saluran }\end{array}$ & 2,461 & 0,096 & 0,237 \\
\hline $\begin{array}{c}\text { hembus } \\
18 " \text { high }\end{array}$ & $\begin{array}{c}\text { ujung } \\
\text { saluran }\end{array}$ & 2,751 & 0,096 & 0,265 \\
\hline $\begin{array}{c}\text { hembus } \\
16 "\end{array}$ & $\begin{array}{c}\text { ujung } \\
\text { saluran }\end{array}$ & 5,466 & 0,096 & 0.526 \\
\hline $\begin{array}{c}\text { blower } \\
\text { buangan } \\
\text { fan }\end{array}$ & 22.090 & 0,008 & 0,179 \\
\hline
\end{tabular}




\subsection{Hasil analisis Kualitas Udara pada alat simulasi}

Hasil evaluasi pada ujung saluran alat simulasi dengan fan hisap dan hembus dengan menyesuaikan standar (Nilai Ambang Batas) yang telah ditetapkan Kepmen555.K/26/M.PE/1995 dapat dilihat pada tabel

Tabel 2. Hasil evaluasi mengenai kualitas udara pada masing-masing fan

\begin{tabular}{|c|c|c|c|c|c|c|c|c|c|c|}
\hline & $\mathrm{Td}$ & $\begin{array}{l}\mathrm{T} \\
\mathrm{W}\end{array}$ & $\mathrm{Te}$ & $\mathrm{RH}$ & $\mathrm{O}_{2}$ & $\mathrm{CO}$ & $\mathrm{CO}_{2}$ & $\mathrm{H}_{2} \mathrm{~S}$ & $\mathrm{CH}_{4}$ & $\begin{array}{l}\text { Efisie } \\
\text { nsi } \\
\text { Kerja }\end{array}$ \\
\hline & ${ }^{\circ} \mathrm{C}$ & ${ }^{\circ} \mathrm{C}$ & ${ }^{\circ} \mathrm{C}$ & $\%$ & $\%$ & $\%$ & $\%$ & $\%$ & $\%$ & $\%$ \\
\hline & \multicolumn{2}{|c|}{$\begin{array}{c}\text { NAB Sesuai } \\
\text { Kepmen } 555 \mathrm{~K}\end{array}$} & $\begin{array}{l}18- \\
24 \\
{ }^{0} \mathrm{C}\end{array}$ & $<85$ & $>19.5$ & $\begin{array}{l}< \\
0,0 \\
005\end{array}$ & $\begin{array}{l}<0 . \\
5\end{array}$ & $<10$ & $\begin{array}{l}<0 \\
25\end{array}$ & \\
\hline $\begin{array}{l}\text { ujung saluran (fan } \\
\text { hembus 18" } \\
\text { kecepatan low) }\end{array}$ & 32 & $\begin{array}{l}28 \\
, 7\end{array}$ & 26 & 65 & 0 & 0 & 0 & 0 & 0 & 88 \\
\hline $\begin{array}{l}\text { ujung saluran (fan } \\
\text { hembus } 18 " \\
\text { kecepatan medium) }\end{array}$ & $\begin{array}{c}31 \\
9\end{array}$ & $\begin{array}{l}28 \\
, 7\end{array}$ & 25,3 & 66 & 0 & 0 & 0 & 0 & 0 & 90 \\
\hline $\begin{array}{l}\text { ujung saluran (fan } \\
\text { hembus 18" } \\
\text { kecepatan high) }\end{array}$ & $\begin{array}{c}31 \\
9\end{array}$ & $\begin{array}{r}28 \\
, 8\end{array}$ & 24,7 & 66 & 0 & 0 & 0 & 0 & 0 & 92 \\
\hline $\begin{array}{l}\text { Point E (fan } \\
\text { hembus } 16 ")\end{array}$ & $\begin{array}{c}32 \\
5\end{array}$ & $\begin{array}{l}28 \\
, 7\end{array}$ & $\begin{array}{c}24 \\
4\end{array}$ & 61 & 0 & 0 & 0 & 0 & 0 & 91 \\
\hline Point E (fan hisap) & $\begin{array}{c}28 \\
9\end{array}$ & $\begin{array}{l}31 \\
, 7\end{array}$ & $\begin{array}{c}26 \\
5\end{array}$ & 70 & 0 & 0 & 0 & 0 & 0 & 80 \\
\hline
\end{tabular}

Dari data hasil evaluasi kualitas udara alat simulasi memiliki temperatur efektif yang cukup tinggi yaitu melebihi nilai ambang batas yang diizinkan oleh Kepmen 555.K/26/M.PE/1995 yaitu $\mathbf{1 8}-\mathbf{2 4}{ }^{\mathbf{0}} \mathrm{C}$, sedangkan untuk kelembaban relatif yang diizinkan oleh Kepmen 555.K/26/M.PE/1995 adalah < 85, tidak melewati nilai ambang batas yang ditetapkan.

\section{KESIMPULAN}

parameter yang diukur oleh PT.AICJ meliputi; data kecepatan angin, luas dimensi terowongan, luas saluran udara, data temperatur udara, serta data kandungan gas dalam udara. desain alat simulasi penulis menggunakan software autocad 2014.
Alat simulasi dibuat menggunakan lempengan besi tebal $1 \mathrm{~mm}$. Dari hasil percobaan Dengan fan ukuran 18" yang digunakan pada percobaan pada alat simulasi, maka diperoleh kecepatan angin 2,751 $\mathrm{m} /$ detik pada ujung saluran, sehingg kuantitas udara yang dialirka sebesar $0,264 \mathrm{~m}^{3} /$ detik. Pada tahanan pengecilan (point B) kecepatan udara yang dialirkan 3,196 m/detik, sehingga kuantitas udara $0,287 \mathrm{~m}^{3} /$ detik. Pada tahanan percabangan (point D) kecepatan udara $0,993 \mathrm{~m} /$ detik, kuantitas udara $0,16 \mathrm{~m}^{2} /$ detik.

Percobaan menggunakan fan hembus ukuran 16"(tenaga lebih besar dibanding ukuran 18") diperoleh data kecepatan angin pada ujung saluran $5,466 \mathrm{~m} /$ detik, maka kuantitas udaranya $0,526 \mathrm{~m}^{2} /$ detik. Pada tahanan pengecilan (point B) kecepatan 
angin sebesar $0,5711 \mathrm{~m} /$ detik, sehingga kuantitas udaranya $0,514 \mathrm{~m}^{3} /$ detik. Pada tahanan percabangan (point D) kecepatan angin sebesar $1,766 \mathrm{~m} /$ detik, maka kuantitas udara $0,283 \mathrm{~m}^{3} /$ detik. Percobaan menggunakan fan hisap pada tahanan pengecilan (point B) kecepatan angin terdeteksi $1,961 \mathrm{~m} /$ detik, maka kuantitas udaranya $0,1765 \mathrm{~m}^{3} /$ detik. Pada tahanan percabangan (pointD) diperoleh data kecepatan angin $0,422 \mathrm{~m} /$ detik, sehingga kuantitas udaranya $0,675 \mathrm{~m}^{3} /$ detik.

Sedangkan pada buangan fan hisap kecepatan angin 22,09 m/detik, maka kuantitas udaranya $0,179 \mathrm{~m}^{3} /$ detik. Maka dapat disimpulkan pada tahanan pengecilan (point B) kecepatan angin lebih besar dibanding titik pengukuran lain, kecuali pada buangan fan hisap, hal ini disebabkan karena luas penampang yang lebih kecil.

Pada tahanan percabangan (point D) kecepatan udara berkurang hampir separuh dari titik pengukuran sebelumnya, dikarenakan jumlah udara yang mengalir terdistribusi pada kedua percangan. Temperature efektif yang diperoleh jika percobaan dilakukan pada ujung saluran menggunakan fan hembus ukran 18" kecepatan maksimum adalah $25,4^{\circ} \mathrm{C}$, menggunakan fan hembus ukuran 16" temperatur efektifnya $25,7^{\circ} \mathrm{C}$ pengukuran dilakukan pada point $\mathrm{E}$ yaitu sebelum ujung saluran. Sedangkan temperatur efektif dari fan hisap adalah $27,7^{\circ} \mathrm{C}$ pengukuran dilakukan pada titik pengukuran point $\mathrm{E}$. kesimpulan Dari data hasil evaluasi kualitas udara alat simulasi memiliki temperatur efektif yang cukup tinggi yaitu melebihi nilai ambang batas yang diizinkan oleh Kepmen 555.K/26/M.PE/1995 yaitu 18 - 24 ${ }^{0} \mathbf{C}$, sedangkan untuk kelembaban relatif yang diizinkan oleh Kepmen 555.K/26/M.PE/1995 adalah < 85, tidak melewati nilai ambang batas yang tetapkan.

\section{DAFTAR PUSTAKA}

Nursyamsu. 2016. Perencanaan Ulang Sistem Jaringan Ventilasi Tambang Dengan Pemasangan Main Fan
Exhaust System di Tunnel I dan II Tambang Batubara Bawah Tanah PT. Allied Indo Coal Jaya. Skripsi. Universitas Negeri Padang

Febrianda Bafnis Ari. 2014. Analisis Sistem Ventilasi Tambang Untuk Kebutuhan Operasional Penambangan Pada Tambang Batubara Bawah Tanah Ombilin 1 (Sawahluwung) PT Bukit Asam-UPO. Skripsi. Universitas Negeri Padang.

Heriyadi Bambang. 2002. Materi Ajar Peranginan Ventilasi Tambang, BDTBT : Sawahlunto.

Hartman L. Howard. 1997. Mine Ventilation and Air Conditioning Third Edition. United States of America.

Janah Nurul. 2014. Kajian Sistem Jaringan Ventilasi Tambang Emas Blok Cikonen PT Cibaliung Sumberdaya. Universitas Islam Bandung, Bandung.

McPherson, M. 1993. Subsurfaces Ventilation and Enviroment Engineering. Chapman and Hall. USA

J. Walsh Joseph. 1915. The Physics and Chemistry of Mining and Mine Ventilation. D Van Nostrand Company. New York.

Keputusan Menteri Pertambangan dan Energi No. 555.K/26/M.PE/1995 Tentang Keselamatan dan Kesehatan Kerja Pertambangan Umum.

United Nations Environtment Programme. 2006. Fan and Blower. Pedoman Efisiensi Energi Untuk Industri di Asia www.energyefficiencyasia.org. UNEP. 
W.L. LE Roux. 1979. Mine Ventilation Notes For Beginner Third Edition.The Mine Ventilation Society Of South Africa.

Worksafe New Zealand. 2014. Ventilation in Underground Mine and Tunnels. New Zealand Goverment. New Zealand.

Ivan Yohanes Marbun. 2013. Studi Mengenai Kondisi Panas dan Kelembapan Area Front GHS Ciguha Utama PT. Aneka Tambang UBPE Pongkor pertambangan Institut Teknilogi Bandung.

Selviana Xu. 2010. Studi Simulasi Laboratorium Mengenai Ventilasi Lokal pada Stope untuk Pembersihan Gas Hasil Peledakan. Institut Teknologi Bandung. 